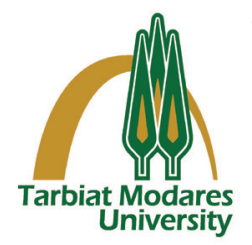

\title{
Antibacterial Effect of Matricaria chamomilla Alcoholic Extract against Drug-Resistant Isolates of Staphylococcus aureus and Pseudomonas aeruginosa
}

\section{A R T I C L E I N F 0}

Article Type

Original Research

Authors

Ania Ahani Azari, $P h D^{1^{*}}$

Ahmad Danesh, $P h D^{1}$

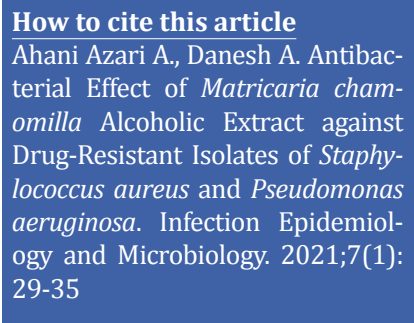

${ }^{1}$ Department of Microbiology, Gorgan Branch, Islamic Azad University, Gorgan, Iran ${ }^{2}$ Infectious Diseases Research Center, Golestan University of Medical Sciences, Gorgan, Iran

\section{* Correspondence}

Address: Department of Microbiology, Gorgan Branch, Islamic Azad University, Gorgan, Iran. ania_783@yahoo.com

\section{A B S T R A C T}

Background: This study aimed to determine antibacterial activity of ethanolic extract of Matricaria chamomilla (chamomile) against methicillin-resistant Staphylococcus aureus (MRSA) and multidrug-resistant (MDR) Pseudomonas aeruginosa strains isolated from clinical specimens. Materials \& Methods: The plant samples were collected, and the flowers and leaves were separated and dried completely in the shade. After grinding, extraction was performed using the maceration method. The extracts of both flowers and leaves were dried at $37^{\circ} \mathrm{C}$ for $24 \mathrm{hrs}$. About $500 \mathrm{mg}$ of the dried plant extract was dissolved in $10 \mathrm{~mL}$ of $5 \%$ dimethyl sulfoxide and sterilized by filtration through a $0.45 \mu \mathrm{m}$ membrane filter. For the antibacterial assay, agar well diffusion and broth microdilution methods were used.

Findings: No inhibitory effect was observed for both extracts against MDR P. aeruginosa isolates in agar well diffusion method. In broth microdilution method, the leaves extract showed inhibitory effect, and its MIC and MBC were determined at 12.5 and $25 \mathrm{mg} / \mathrm{mL}$ concentrations, respectively. The flowers extract showed antibacterial activity against most MRSA isolates. The extract of leaves demonstrated inhibitory effect on 7 MRSA isolates. The MIC and MBC of flowers extract were determined at concentrations of 6.25 and $12.5 \mathrm{mg} / \mathrm{mL}$ for most MRSA isolates, while MIC and MBC of leaves extract were 12.5 and $25 \mathrm{mg} / \mathrm{mL}$ for a few MRSA isolates, respectively.

Conclusion: In this study, the ethanolic extract of chamomile leaves showed antibacterial activity against MDR P. aeruginosa isolates; meanwhile, the flowers extract showed better activity against MRSA isolates.

Keywords: Antibacterial effect, Drug-resistance, Matricaria chamomilla, Pseudomonas aeruginosa, Staphylococcus aureus.

\section{CITATION LINKS}

[1] Kasra-Kermanshahi R, Mobarak-Qamsari E. Inhibition effect of lactic acid ... [2] Meshkibaf MH, Abdollahi A, Fasihi Ramandi M, Adnani Sadati SJ, Moravvej A, Hatami S. Antibacterial effects of ... [3] Rizwana H, Alwhibi M, Soliman D. Antimicrobial activity and chemical composition ... [4] Yarnell E. Abascal K. Herbal support for methicillin-resistant ... [5] Ompal S, Zakia KH, Neelam M, Manoj Kumar S. Chamomile (Matricaria chamomilla L.): An ... [6] Sharifi-Rad M, Nazaruk J, Polito L, Morais-Braga MF, Rocha JE, Coutinho HD, et al. Matricaria genus as a source of antimicrobial agents: ... [7] Das S, Horváth B, Šafranko S, Joki'c S, Széchenyi A, K"oszegi T. Antimicrobial activity of ... [8] McKay DL, Blumberg JB. A review of the bioactivity and potential ... [9] Izadi Z, Modarres Sanavi SAM, Sorooshzadeh A, Esna-Ashari M, Davoodi P. Antimicrobial activity of chamomile (Matricaria chamomilla L.) and feverfew (Tanacetum parthenium L.). Armaghane-Danesh J Yasuj .... [10] Imeni N, Qayami Rad M. In vitro antibacterial effect of ethanolic extract of Calendual officinalis L. againstStaphylococcus aureus, Enterococcus faecalis, Escherichia coli, and Pseudomonas ... [11] Poudineh F, Ahani Azari A, Fozouni L. Incidence of multidrug-resistant, extensively ... [12] Sadat SS, Ahani Azari A. Frequency of multidrugresistant, extensively ... [13] Datta P, Gulati N, Singla N, Rani Vasdeva H, Bala K, Chander J, et al. Evaluation of ... [14] Magiorakos AP, Srinivasan A, Carey RB, Carmeli Y, Falagas ME, Giske CG, et al. Multidrug-resistant, extensively ... [15] Alkuraishy H, Al-Gareeb A, Albuhadilly A. Alwindy S. In vitro assessment of the ... [16] Dadgar T, Ghaemi E, Bazouri M, Asmar M, Mazandarani M, Seifi A, et al. Antibacterial effect .... [17] Carvalho AF, Silva DM, Silva TRC, Scarcelli E, Manhani MR. Evaluation of the ... [18] Saderi H, Olia P, Hashemi SR. Effect of Matricaria chamomilla L essential oil on .... [19] Owlia P, Saderi H, Rasooli I, Sefidkon F. Antimicrobial characteristics ... [20] Solidônio EG, Burle YS, Silva PA, Vicalvi MCV, de Souza IFAC, Silva GR, et al. Evaluation of antimicrobial activity of extracts of chamomile (Matricaria recutita L.) obtained from irradiated and non-irradiated ... [21] Eslami G, Hashemi A, Karimi Yazdi MM, Esmaeili Benvidi M, Khiabani Rad P, Lotfolah Moradi S, et al. Antibacterial effects of Zataria multiflora, Ziziphus, Chamomile, and Myrtus communis methanolic extracts on IMP-Type ... [22] Oliveira Ribeiro S, Fontaine V, Mathieu V , Zhiri A, Baudoux D, Stévigny C, et al. Antibacterial and cytotoxi ... [23] Fabri R, Nogueira M, Dutra L, Bouzada M, Scio E. Antioxidant and ...
Received: October 25,2020

Accepted: December 15,2020

Published: January 23,2021 


\section{Introduction}

The emergence of drug resistant bacteria and the decline in the discovery of new antibiotics has created a global health crisis due to limited treatment options. Thus, there is a crucial need to find new and effective antibacterial agents as alternatives to antibiotics ${ }^{[1-2]}$. Herbs and plant-derived products have a long history of safe use as natural products in the treatment of various diseases ${ }^{[3]}$. The use of medicinal plants lessens antibiotic usage and thus inhibits rapid emergence and spread of resistant bacteria ${ }^{[4]}$.

One such plant is Matricaria chamomilla (German chamomile), a well-known medicinal flowering plant belonging to the Asteraceae family, which grows in temperate regions of Europe, Asia, America, and Africa [5-6]. This plant has a branched, straight, and smooth stem, growing to a height of 15-60 cm, with long and narrow bipinnate or tripinnate leaves and flowers borne in paniculate flower heads [6]. Chamomile has an extensive range of effects, including antioxidant, antimicrobial, antitumor, antiinflammatory, and antiviral activities ${ }^{[7]}$. The chamomile flowers contain many chemical constituents including volatile terpenoids (e.g., $\alpha$-bisabolol, bisabolol oxide $\mathrm{A}$ and $B, \beta$-trans-farnesene and chamazulene), sesquiterpene lactones such as matricin, and phenolic compounds (flavonoids, coumarins and phenolic acids) ${ }^{[8]}$. There is a large number of published data on the antibacterial effects of this herb and its chemical constituents [6]; however, there are differences in the extent of these effects because antimicrobial activity is attributed to its chemical composition that largely depends on the type of plant variety, growth stage or collection time of plant, and many ecological factors such as plant habitat [9]. Therefore, due to the wide geographical distribution of chamomile in Iran, the study of antimicrobial properties of this plant in different regions is of great importance.

Objectives: The aim of this study was to evaluate antibacterial activity of ethanolic extract of German chamomile collected from Ziarat village, situated in southern heights of Gorgan, Golestan province, against methicillin-resistant Staphylococcus aureus (MRSA) and multidrug-resistant (MDR) Pseudomonas aeruginosa strains isolated from clinical specimens.

\section{Materials and Methods}

Plant materials and preparation of extracts: The chamomile leaves and flowers were collected from Ziarat village located $17 \mathrm{~km}$ south of the city of Gorgan, Golestan province in May 2019 and approved in the herbarium of Islamic Azad University of Gorgan. Then the required parts of the plants were seperated and placed in the shade to dry. After grinding, extraction was performed using the maceration method. To do so, $10 \mathrm{~g}$ of plant powder was soaked in $200 \mathrm{~mL}$ of pure ethanol and left in the dark for 72 hrs. After that, the resulting solution was filtered through a filter paper. The extract was concentrated using a rotary evaporator at $45{ }^{\circ} \mathrm{C}$ and dried at $37{ }^{\circ} \mathrm{C}$ for 24 hrs. To obtain a concentration of 50 $\mathrm{mg} / \mathrm{mL}$ of the extract, $500 \mathrm{mg}$ of the dried plant extract was dissolved in $10 \mathrm{~mL}$ of $5 \%$ dimethyl sulfoxide (DMSO) and sterilized by filtration through a $0.45 \mu \mathrm{m}$ membrane filter. Different concentrations of the extract $(25,12.5,6.25,3.12 \mathrm{mg} / \mathrm{mL})$ were prepared by serial dilution method [10].

Microorganisms: The antibacterial effect of each extract at different concentrations was assessed against MRSA $(n=24)$ and MDR $P$. aeruginosa $(\mathrm{n}=16)$ isolates from our previous study ${ }^{[11-12]}$. In previous study, methicillin resistance was evaluated using 30 $\mu$ g cefoxitin disk $(\leq 21 \mathrm{~mm}$ indicated MRSA) and $1 \mu \mathrm{g}$ oxacillin disk $(\leq 10 \mathrm{~mm}$ indicated 
MRSA) [13]. In addition, $P$. aeruginosa isolates that were resistant to one or more antimicrobial agents in three or more antimicrobial categories were considered as MDR ${ }^{[14]}$. To determine the antibacterial effect of extracts, agar well diffusion and broth microdilution methods was used. In both methods, S. aureus ATCC 29213 and P. aeruginosa ATCC 27853 strains were used as control.

Agar well diffusion method. About $30 \mu \mathrm{L}$ of the prepared extract at different dilutions $(50,25,12.5,6.25,3.12 \mathrm{mg} / \mathrm{mL})$ was poured in each of the 6 -mm-deep wells punched into the Müeller-Hinton agar plates previously seeded with $10^{6} \mathrm{CFU} / \mathrm{mL}$ of the test bacteria pre-cultured in nutrient broth. After $24 \mathrm{hrs}$ of incubation at $37^{\circ} \mathrm{C}$, the diameter of the clear inhibition zone formed around each well was measured in millimeters. In this study, vancomycin antibiotic (30 $\mu \mathrm{g})$ as well as amikacin (30 $\mu \mathrm{g}$ ) as a positive control (with inhibition zone) and DMSO as a negative control (without inhibition zone) were used. This test was done in triplicate, and the mean values were recorded [10].

Broth microdilution method. In this method, a microtiter plate was used to determine the minimum inhibitory concentration (MIC) and minimum bactericidal concentration (MBC). In this test, $100 \mu \mathrm{L}$ of Müeller-Hinton broth was poured into 1 to 9 wells of a sterile roundbottom 96-well microplate. Afterwards, $100 \mu \mathrm{L}$ of different dilutions of each extract were added from the highest to the lowest concentration into 1 to 9 microplate wells, respectively. Thereafter, $1 / 100$ dilutions of the pre-cultured test bacteria with $10^{6}$ $\mathrm{CFU} / \mathrm{mL}$ in nutrient broth were prepared and added to 1 to 9 wells. In each series, the well No. 10 containing culture medium and bacterial suspension was considered as positive control, and the well No. 11 containing sterile Müeller-Hinton broth culture medium (no growth) and the well No. 12 containing culture medium and extract (no growth) were considered as negative control. After incubation at $37{ }^{\circ} \mathrm{C}$ for 24 hrs, bacterial growth rate at $630 \mathrm{~nm}$ was determined using ELISA microplate reader. The lowest extract concentration at which no growth or a decrease in OD was observed, was considered as MIC. To determine the MBC, the contents of the wells in which no growth was observed were cultured on Müeller-Hinton agar and placed in an incubator at $37^{\circ} \mathrm{C}$ for $24 \mathrm{hrs}$. The lowest extract concentration at which no bacterial growth was observed, was considered as MBC [10].

\section{Findings}

The chamomile flowers extract showed antibacterial activity against 20 MRSA isolates (Table 1). The chamomile leaves extract demonstrated an inhibitory effect on 7 MRSA isolates. The MIC and MBC of chamomile flowers extract were determined at 6.25 and $12.5 \mathrm{mg} / \mathrm{mL}$ concentrations for 14 MRSA isolates, while these values were 12.5 and $25 \mathrm{mg} / \mathrm{mL}$ for 6 MRSA isolates, respectively. The MIC and MBC of chamomile leaves extract were 12.5 and $25 \mathrm{mg} / \mathrm{L}$ for 7 MRSA isolates, respectively (Table 2).

Based on the results of agar well diffusion method, none of the extracts had inhibitory effect against MDR P. aeruginosa isolates. As shown in Table 3, the chamomile leaves extract demonstrated a MIC of $12.5 \mathrm{mg} /$ $\mathrm{mL}$ against all MDR $P$. aeruginosa isolates as control strain. This extract had a bactericidal effect on the isolates at a concentration of 25 $\mathrm{mg} / \mathrm{mL}$ that was considered as MBC.

As a result, the chamomile leaves extract showed antibacterial activity against MDR $P$. aeruginosa isolates; meanwhile, the flowers extract showed better activity against MRSA isolates. 
Table 1) Mean diameter of inhibitory zone ( $\mathrm{mm}$ ) in different concentrations of the test extracts in agar well diffusion method against the MRSA isolates

\begin{tabular}{|c|c|c|c|c|c|c|c|c|}
\hline \multirow{2}{*}{ Microorganism } & \multirow{2}{*}{$\begin{array}{l}\text { Plant part } \\
\text { used }\end{array}$} & \multicolumn{5}{|c|}{$\begin{array}{l}\text { Concentration of the chamomile } \\
\text { flower and leaves extracts }(\mathrm{mg} / \mathrm{ml})\end{array}$} & \multirow{2}{*}{$\begin{array}{l}\text { Negative } \\
\text { control: DMSO }\end{array}$} & \multirow{2}{*}{$\begin{array}{l}\text { Positive } \\
\text { control: } \\
\text { Vancomycin }\end{array}$} \\
\hline & & 3.12 & 6.25 & 12.5 & 25 & 50 & & \\
\hline $\begin{array}{l}\text { MRSA } \\
(n=6)\end{array}$ & Flower & - & - & - & - & 12.3 & - & 13.3 \\
\hline $\begin{array}{l}\text { MRSA } \\
(n=14)\end{array}$ & Flower & - & - & - & 10.3 & 12.7 & - & 13.1 \\
\hline $\begin{array}{l}\text { MRSA } \\
(n=4)\end{array}$ & Flower & - & - & - & - & - & - & 13 \\
\hline $\begin{array}{l}\text { MRSA } \\
(n=7)\end{array}$ & Leaves & - & - & - & - & 10.1 & - & 13 \\
\hline $\begin{array}{l}\text { MRSA } \\
(n=17)\end{array}$ & Leaves & - & - & - & - & - & - & 13.3 \\
\hline $\begin{array}{c}\text { S. aureus ATCC } \\
29213\end{array}$ & Flower & - & - & - & - & 12.1 & - & 15 \\
\hline $\begin{array}{c}\text { S. aureus ATCC } \\
29213\end{array}$ & Leaves & - & - & - & - & 9.8 & - & 15 \\
\hline
\end{tabular}

Table 2) Minimum inhibitory concentrations $(\mathrm{mg} / \mathrm{ml})$ of the test extracts on the MRSA isolates by using the microdilution method

\begin{tabular}{|c|c|c|c|c|c|c|}
\hline \multirow{2}{*}{ Microorganism } & \multirow{2}{*}{ Plant part used } & \multicolumn{5}{|c|}{ Concentration of the flower and leaves extracts $(\mathrm{mg} / \mathrm{ml})$} \\
\hline & & 3.12 & 6.25 & 12.5 & 25 & 50 \\
\hline $\begin{array}{l}\text { MRSA } \\
(n=6)\end{array}$ & Flower & + & + & - & - & - \\
\hline $\begin{array}{c}\text { MRSA } \\
(n=14)\end{array}$ & Flower & + & - & - & - & - \\
\hline $\begin{array}{l}\text { MRSA } \\
(n=4)\end{array}$ & Flower & + & + & + & + & + \\
\hline $\begin{array}{l}\text { MRSA } \\
(n=7)\end{array}$ & Leaves & + & + & - & - & - \\
\hline $\begin{array}{c}\text { MRSA } \\
(n=17)\end{array}$ & Leaves & + & + & + & + & + \\
\hline S. aureus ATCC 29213 & Flower & + & + & - & - & - \\
\hline S. aureus ATCC 29213 & Leaves & + & + & + & + & + \\
\hline
\end{tabular}


Table 3) Minimum inhibitory concentrations $(\mathrm{mg} / \mathrm{ml})$ of the test extracts on the MDR $P$. areuginosa isolates by using microdilution method

\begin{tabular}{|c|c|c|c|c|c|c|}
\hline \multirow{2}{*}{ Microorganism } & \multirow{2}{*}{$\begin{array}{l}\text { Plant part } \\
\text { used }\end{array}$} & \multicolumn{5}{|c|}{ Concentration of the plant extracts $(\mathrm{mg} / \mathrm{ml})$} \\
\hline & & 3.12 & 6.25 & 12.5 & 25 & 50 \\
\hline MDR P. areuginosa & Leaves & + & + & - & - & - \\
\hline MDR $P$. areuginosa & Flower & + & + & + & + & + \\
\hline P. aeruginosa ATCC 27853 & Leaves & + & + & - & - & - \\
\hline P. aeruginosa ATCC 27853 & Flower & + & + & + & + & + \\
\hline
\end{tabular}

\section{Discussion}

In recent years, an increase in antibiotic resistance and the emergence of drugresistant bacteria have necessitated efforts to find novel antimicrobial agents. Recent studies have focused on herbs and plantderived products as a source of natural antimicrobial substances and mostly reported their effectiveness against various pathogenic bacteria causing different infectious diseases. In this study, antibacterial activity of the chamomile flowers and leaves ethanolic extracts was tested against MRSA and MDR P. areuginosa strains isolated from clinical specimens.

According to the results, the chamomile flowers extract showed antibacterial activity against most MRSA isolates, and its MIC and MBC were 6.25 and $12.5 \mathrm{mg} / \mathrm{mL}$, respectively; however, a study in Iraq reported MIC and $\mathrm{MBC}$ values of $15 \mathrm{mg} / \mathrm{mL}$ for $S$. aureus NCIM $2243^{[15]}$. In a study by Dadgar et al. (2007), the mean inhibition zone diameter of the chamomile flower ethanolic extract (4 mg/mL) against MRSA and methicillinresistant $S$. aureus (MSSA) was reported as 10.6 and $8.8 \mathrm{~mm}$, respectively ${ }^{[16]}$. Carvalho et al. (2014) reported that flower ethanolic extract of chamomile had no effect against $S$. aureus isolates [17].

In the current study in agreement with the studies conducted by Saderi et al. (2007) and Owlia et al. (2010), no inhibitory effect was observed for the chamomile ethanolic extracts against $P$. aeruginosa isolates in agar well diffusion method ${ }^{[18-19]}$. In contrast, a study in Brazil reported that the growth of P. aeruginosa was inhibited by crude flower ethanolic extract using broth dilution $(1 \mathrm{~g} / \mathrm{mL})$, and inhibition zone diameter was reported as $10 \mathrm{~mm}$ using agar diffusion ${ }^{[15]}$. Solidônio et al. (2015) in Brazil used disk diffusion method to evaluate antibacterial activity of ethanolic extract of chamomile, but no inhibitory activity was observed against $P$. aeruginosa strains ${ }^{[20]}$.

Consistent with the present study findings, in a study by Eslami et al. (2016), the MIC and MBC of chamomile leaves ethanolic extract were reported 12.5 and $25 \mathrm{mg} / \mathrm{mL}$ for all metallo-beta-lactamase-producing $P$. aeruginosa isolates, respectively; however, in another study in Iraq, different values were reported for MIC and MBC of chamomile (32 and $64 \mathrm{mg} / \mathrm{mL}$ ) ${ }^{[21]}$. In Belgium, Oliveira Ribeiro et al. (2020) reported antibacterial activity of chamomile flower essential oil against $P$. aeruginosa and $S$. aureus isolates at a concentration of $>1000 \mathrm{ug} / \mathrm{mL}^{[22]}$. In another study, methanolic extract of chamomile leaves presented a MIC of $78 \mu \mathrm{g} / \mathrm{mL}$ against $P$. aeruginosa isolates ${ }^{[23]}$.

Considering the results of the aforementioned and the present studies, there are different 
reports about antibacterial activity of the chamomile flowers and leaves ethanolic extracts, which could be attributed to the differences in some factors as follows: geographical location of plant collection, season of harvest, method of extraction, extract concentration, plant part (s) used, test organism, and antibacterial assay ${ }^{[6,9]}$. Therefore, further studies are recommended to be performed in order to investigate the antibacterial activity of these herbal extracts. In future studies, the use of higher concentrations of extracts as well as different solvents and extraction methods is suggested.

\section{Conclusion}

In this study, the chamomile leaves extract showed antibacterial activity against MDR $P$. aeruginosa isolates; meanwhile, the flowers extract showed better activity against MRSA isolates.

Acknowledgements: The Department of Microbiology of the Islamic Azad University, Gorgan Branch is acknowledged for providing facilities to accomplish the present study.

Ethical Permissions: This study was approved by the Academic Committee of the Islamic Azad University, Gorgan Branch.

Conflicts of Interests: The authors declared no conflict of interests.

Authors' Contribution: Conceptualization: AAA; Data curation and formal analysis: AD; Investigation: AAA; Methodology and project administration: AAA; Supervision: AAA; Validation: AD; Writing of original draft: AAA; Writing, reviewing, and editing: AD.

Fundings: None declared by authors. Consent to participate: A written informed consent was obtained from all patients.

\section{References}

1. Kasra-Kermanshahi R, Mobarak-Qamsari
E. Inhibition effect of lactic acid bacteria against foodborne pathogen, Listeria monocytogenes. Appl Food Biotechnol. 2015;2(4):11-9.

2. Meshkibaf $\mathrm{MH}$, Abdollahi A, Fasihi Ramandi M, Adnani Sadati SJ, Moravvej A, Hatami S. Antibacterial effects of hydroalcoholic extracts of Ziziphora tenuior, Teucrium polium, Barberis corcorde, and Stachys inflate. J Semnan Univ Med Sci. 2010;11(4):24-245.

3. Rizwana H, Alwhibi M, Soliman D. Antimicrobial activity and chemical composition of flowers of Matricaria aurea a native herb of Saudi Arabia. Int J Pharmacol. 2016;12: 576-86.

4. Yarnell E. Abascal K. Herbal support for methicillin-resistant Staphylococcus aureus infections. Altern Complement Ther. 2009;15(4):189-95.

5. Ompal S, Zakia KH, Neelam M, Manoj Kumar S. Chamomile (Matricaria chamomilla L.): An overview. Pharmacogn Rev. 2011;5(9): 82-95.

6. Sharifi-Rad M, Nazaruk J, Polito L, Morais-Braga MF, Rocha JE, Coutinho HD, et al. Matricaria genus as a source of antimicrobial agents: From farm to pharmacy and food applications. Microbiol Res. 2018;215:76-88.

7. Das $S$, Horváth $B$, Šafranko $S$, Joki'c $S$, Széchenyi A, K"oszegi T. Antimicrobial activity of chamomile essential oil: Effect of defferent formulations. Molecules. 2019;24(23): 4321.

8. McKay DL, Blumberg JB. A review of the bioactivity and potential health benefits of chamomile tea (Matricaria recutita L.). Phytother Res. 2006;20(7): 519-30.

9. Izadi Z, Modarres Sanavi SAM, Sorooshzadeh A, Esna-Ashari M, Davoodi P. Antimicrobial activity of chamomile (Matricaria chamomilla L.) and feverfew (Tanacetum parthenium L.). ArmaghaneDanesh J Yasuj Univ Med Sci. 2013;18(1): 
31-43.

10. Imeni N, Qayami Rad M. In vitro antibacterial effect of ethanolic extract of Calendual officinalis L. against Staphylococcus aureus, Enterococcus faecalis, Escherichia coli, and Pseudomonas aeruginosa. Zanko J Med Sci. 2014;19(62):61-9.

11. Poudineh F, Ahani Azari A, Fozouni L. Incidence of multidrug-resistant, extensively drug-resistant, and pandrugresistant Pseudomonas aeruginosa strains isolated from clinical specimens. Infect Epidemiol Microbiol. 2020;6(3): 211-7.

12. Sadat SS, Ahani Azari A. Frequency of multidrug-resistant, extensively drug-resistant, and pandrug-resistant phenotypes among clinical isolates of Staphylococcus aureus. Infect Epidemiol Microbiol. 2020; 6(4).

13. Datta P, Gulati N, Singla N, Rani Vasdeva $\mathrm{H}$, Bala K, Chander J, et al. Evaluation of various methods for the detection of meticillin-resistant Staphylococcus aureus strains and susceptibility patterns. J Med Microbiol. 2011;60(11):1613-6.

14. Magiorakos AP, Srinivasan A, Carey RB, Carmeli Y, Falagas ME, Giske CG, et al. Multidrug-resistant, extensively drug-resistant, and pandrug-resistant bacteria: An international expert proposal for interim standard definitions for acquired resistance. Clin Microbiol Infect. 2012;18(3):268-81.

15. Alkuraishy $\mathrm{H}, \mathrm{Al}$-Gareeb A, Albuhadilly A. Alwindy S. In vitro assessment of the antibacterialactivity of Matricariachamomile alcoholic extract against pathogenic bacterial strains. Br Microbiol Res J. 2015;7(2):55-61

16. Dadgar T, Ghaemi E, Bazouri M, Asmar M, Mazandarani M, Seifi A, et al. Antibacterial effect of 20 species of medicinal plants against methicillin-resistant and sensitive to Staphylococcus aureus. J Gorgan Univ Med Sci. 2007;9(1):55-62.
17. Carvalho AF, Silva DM, Silva TRC, Scarcelli E, Manhani MR. Evaluation of the antibacterial activity of ethanolic and cyclohexane extracts of chamomile flowers (Matricaria chamomilla L.). Rev Bras Plantas Med. 2014;16(3):521-6. 18. Saderi H, Olia P, Hashemi SR. Effect of Matricaria chamomilla L essential oil on biofilm production in Pseudomonas aeruginosa. Iran J Med Microbiol. 2007;1(2):9-14.

19. Owlia P, Saderi H, Rasooli I, Sefidkon F. Antimicrobial characteristics of some herbal oils on Pseudomonas aeruginosa with special reference to their chemical compositions. Iran J Pharm Res. 2010;8(2):107-14.

20. Solidônio EG, Burle YS, Silva PA, Vicalvi MCV, de Souza IFAC, Silva GR, et al. Evaluation of antimicrobial activity of extracts of chamomile (Matricaria recutita L.) obtained from irradiated and non-irradiated samples. In: MéndezVilas A, Ed. The battle against microbial pathogens: Basic science, technological advances and educational programs. Formatex; 2015, 151-6.

21. Eslami G, Hashemi A, Karimi Yazdi MM, Esmaeili Benvidi M, Khiabani Rad P, Lotfolah Moradi S, et al. Antibacterial effects of Zataria multiflora, Ziziphus, Chamomile, and Myrtus communis methanolic extracts on IMP-Type metallo-beta-lactamase-producing Pseudomonas aeruginosa. Arch Clin Infect Dis. 2016;11(1):1-5.

22. Oliveira Ribeiro S, Fontaine V, Mathieu V , Zhiri A, Baudoux D, Stévigny C, et al. Antibacterial and cytotoxic activities of ten commercially available essential oils. Antibiotics. 2020;9(10):717.

23. Fabri R, Nogueira M, Dutra L, Bouzada M, Scio E. Antioxidant and antimicrobial potential of Asteraceae species. Rev Bras Plantas Med. 2011;13(2):183-9. 